\title{
Methodological challenges of trans-disciplinary research: some systemic reflections
}

\author{
Ray Ison \\ Professor of Systems, The Open University, Faculty of Maths, Computing and Technology, Open Systems Research Group, \\ Milton Keynes, UK
}

\author{
Keywords: \\ research practice; \\ trans-disciplinarity; \\ social learning; \\ systems approaches
}

Mots-clés : pratiques de recherche transdisciplinarité ; apprentissage social ; démarche système

\begin{abstract}
This essay was written in response to an invitation by the editors of NSS issued after the author had reviewed the paper entitled "Methodological challenges of trans-disciplinary research" submitted by Christian Pohl and Gertrude Hirsch-Hadorn (see Pohl and Hirsch Hadorn, 2008). The essay provides an accounting for the transformation in my emotioning as I read the submitted paper by introducing three sets of distinctions: (i) a model of research practice; (ii) an explication of the nature of research situations and (iii) an exploration of the different intellectual lineages that give rise to contemporary systems approaches. I then return to the paper that was under review through the lens of trans-disciplinary research as social learning.
\end{abstract}

\begin{abstract}
Résumé - Défis méthodologiques de la recherche transdisciplinaire : quelques réflexions systémiques. Cet essai résulte d'une invitation des rédacteurs de NSS à Ray Ison qui lui a été faite à la suite de ses commentaires sur l'article intitulé «Methodological Challenges of trans-disciplinary Research » proposé par Christian Pohl et Gerturde Hirsch-Hadorn (voir Pohl et Hirsch-Hadorn, 2008), qui lui avait été soumis pour lecture. L'essai qui suit rend compte, dans un premier temps, de ses réactions à la lecture de cet article à partir de trois entrées : a) un modèle des pratiques de recherche, issu de sa propre tradition venant de la Soft Systems Methodology britannique, b) Une explication de la nature des «situations de recherche », qu'il présente comme des situations non banales, à aborder avec précaution, c) Une exploration des différentes filiations intellectuelles à l'origine de la démarche systémique contemporaine. Il revient ensuite à l'article de Pohl et Hirsch-Hadorn, qu'il commente en l'abordant par l'angle de la recherche transdisciplinaire en tant qu'apprentissage social. Il développe ainsi un point de vue conceptuel d'un ordre différent de celui choisi par les auteurs de l'article, pointant là où ces approches divergent et là où elles se rencontrent.
\end{abstract}

My experience of reviewing the paper by Pohl and Hirsch-Hadorn gave rise to two contrasting emotions the first was one of excitement that the methodological basis of trans-disciplinarity was being taken seriously by this group of researchers and that it was a debate that NSS considered worthy of fostering. This emotion also triggered a sense of anticipation - I was struck by the relevance of their opening questions:

- What are the methods that you use?

- What concepts and theory is your research based on?

- And what skills do I have to develop to become a transdisciplinary researcher?

Corresponding author: r.l.ison@open.ac.uk

Ray Ison is also Professor at Uniwater, Monash Sustainability Institute, Monash University, Melbourne, Australia.
However, after reading the whole paper, my dominant emotion was one of anxiety. Why was this so? This essay is the explanation I offer. It is based on the invitation from the editors of NSS to make this contribution and my consideration of the purpose of this reflection: i.e. to explain this transformation in my emotions! Lest readers become alarmed at this point let me explain that my perspective is very much influenced by a range of systems scholars but particularly the work of Humberto Maturana and the late Francisco Varela, two systemic biologists and epistemologists (e.g. Maturana and Varela, 1987; Maturana, 1988). From this perspective, rationality is merely one of the many different forms of emotioning available to us when we do what we do! For them, emotioning, which has a physiological basis, is a key 
characteristic of being human ${ }^{1}$. My point here is to offer an explanation of what happened in the flow of my emotioning as I read and reviewed this paper. A major point of my explanation will be that an explanation is never independent of the explainer and of the context in which it is offered. Furthermore I will argue that this is profoundly important to how we understand and do something to which we ascribe the label "transdisciplinary research".

I have chosen to begin this reflection in this way for an additional reason. Elsewhere I have been critical of the lack of epistemological awareness amongst researchers citing the example of referees who impose their epistemological preferences on the review process without awareness that that is what they are doing (Ison \& Schlindwein, 2006). So I do not want to fall into the same trap! Or put another way, I want to take responsibility for my own epistemological commitments. One way to do this is to be aware that we all act out of our own, unique, traditions of understanding.

\section{We act out of our traditions of understandings}

As humans we have a biological and social history from which our traditions of understanding arise. Russell and Ison (2007) describe how our models of understanding grow out of traditions; a tradition is a network of prejudices that provides possible answers and strategies for action. Another way of defining tradition is as a network of pre-understandings (because the word prejudices may be literally understood as a pre-understanding). From this perspective, traditions are not only ways to see and act but a way to conceal that can operate at the individual, group, organization or cultural level. ${ }^{2}$

\footnotetext{
1 Maturana (pers. comm.) says: "What we distinguish in daily life as we distinguish emotions, are kinds of relational behaviors, not particular doings. And what we connote biologically as we speak of emotions referring to ourselves or to other animals, are body dynamic dispositions (involving the nervous system and the whole body) that determine what we or they can do or not do, in what relations we or they can enter or not enter, at any moment. As a result, different emotions can be fully characterized as different domains of relational behaviors, or physiologically, as dynamic body dispositions for relational behaviors." He goes on to explain the origins of humanness as: "what must have begun then [in human evolution] must have been living in the braiding of languaging and emotioning that we call conversations, constituting human living, a living in networks of conversations".

2 In a critique of this essay Eli Benneker (pers. comm., June, 2008) said: "Every model or system is a way of seeing and, therefore, a way of not seeing. Model as to focus our attention on particulars and, as any physicist will argue, the cost of focus is what you do not see. [For example] binoculars make some things clear by reducing the field of vision."
}

A risk is that a tradition can become a blind spot when it evolves into practice without critical reflection. As this also applies to the practice of refereeing, I want, in this essay, to create the circumstances for critical reflection by offering some explanations which might enable the reader to begin to appreciate the tradition of understanding from which I engaged with the paper under review. It is also an accounting for the transformation in my emotioning. I begin by introducing three sets of distinctions. ${ }^{3}$ The first is a model of research practice, the second is an explication of the nature of research situations and the third is an exploration of the different intellectual lineages that give rise to contemporary systems approaches. I then return to the paper that was under review (Pohl and Hirsch-Hadorn, 2008) through the lens of trans-disciplinary research as social learning.

\section{Doing research - a conceptual model of practice}

As I understood their paper the authors were implicitly setting out to develop a praxeology for trans-disciplinary research ${ }^{4}$. The term praxeology means to develop a theory of practical action, in this case as a means to orchestrate effective action amongst individuals who have different disciplinary backgrounds. Consistent with earlier scholars I take "trans" to mean across, or "meta" and thus trans-disciplinarity to be either a "metadiscipline" or a form of praxis that crosses disciplines. However, before arguing what trans-disciplinarity is or is not and thus what an effective praxis might be, I want to present a general model of research as a form of practice (Fig. 1) which is designed to be used heuristically. In its simplest form, research practice involves a researcher with a framework of ideas (F), a methodology (M) and an area of application (A), a "real world" situation. What more can be said about this conceptualisation? Well we can posit that many researchers, but not all, actively choose a theoretical framework from which to engage with their research questions - for example actor network theory might be chosen as the theoretical framework

\footnotetext{
See Ison and Russell (2000) for the argument that experience arises out of the act of making new distinctions. In offering these models or heuristics I do not assume that they will give rise to new distinctions on the part of the reader - they are designed with this hope in mind, but that is all it is, a hope!

${ }^{4}$ On the basis of some of the references provided by the authors (e.g. Pohl and Hirsch Hadorn, 2007; Pohl et al., 2008) I felt that the authors' explication of a praxeology might not be well served by the paper they submitted, in that I considered the core arguments to have not been sufficiently synthesised or because a lot of material could not be reduced to the length required by NSS paper format. In fact, as I now understand it, the authors drew heavily on the Handbook of Transdisciplinary Research (Hirsch-Hadorn, et al., 2008).
} 


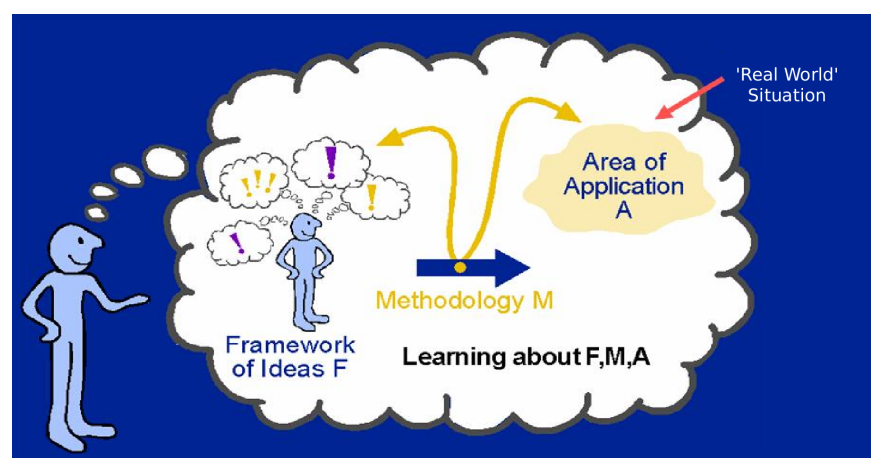

Fig. 1. An heuristic model of research as a form of practice (source: Blackmore et al., 2007, following Checkland, 1985).

from which to answer questions about a particular social situation. On the other hand epistemologically naive empiricists may argue, or imagine, that they come to situations as if they were theory free. Equally, social researchers who are theoretically adept may forget that the purposeful choice of any particular theory does not negate the understanding that as human beings with a history they too have traditions of understanding which they bring forth in the moment, and that these, as embodied understandings, may be different to the theories they espouse in moments of rational reflection.

Most commonly, the idea of methodology is associated with some form of rational choice and with this choice a range of methods and techniques become deployed. In Ison and Russell (2000), we argue that methodology, rather than being simply the logos of method, is something that has to be experienced where the key experience is that of the degree of coherence, or congruence between espoused theory and practice ${ }^{5}$.

In Figure 1, I retain the language of Checkland's (1985) original articulation of what he called the FMA model. In it he refers to the "area of application", but I prefer situation or "real world situation"6. The phrase "area of application" arises from a preoccupation with methodology - i.e. this is the area into or onto which this $\mathrm{M}$ will be applied ${ }^{7}$. My preference for the term "situation" has a particular rationale which I describe below. For the moment let's accept that a generic description of research as a practice

\footnotetext{
5 This reflection has been triggered by our experience of teaching systems, a field in which many claims about methodology are made and in which many students find it difficult to move beyond the methodical (i.e. recipe-like) use of particular methodologies. My main point is that methodology arises as reflection on praxis, in context specific ways, rather than existing a priori.

6 The inverted commas around "real world" denote Checkland's original distinctions between situation and the "conceptual world" of the researcher/practitioner - this is a distinction to aid praxis, not a commitment, on my part, to a "reality" independent of an observer.

7 In Checkland and Holwell (1998) the A was described as "area of concern" (p. 23).
}

comprises a researcher $(\mathrm{R})$ with a history, a tradition of understanding, possibly a chosen framework of ideas $(\mathrm{F})$, a chosen $\mathrm{M}$ and a situation (A) in which the research is practised as a means of understanding, discovering, describing or changing something. If we consider Figure 1 systemically, as a whole then there are emergent properties of this practice; these include the possibility of: ${ }^{8}$

- learning about each or all of F, M or A;

- considering the conduct of the research - the act of connecting $\mathrm{F}, \mathrm{M}$ and $\mathrm{A}$ as a form of performance - e.g. how effective was the research (first-order effectiveness)?

- taking a meta or second order perspective on the researching system-environment relationship (as depicted in Figure 1 by the person operating at two levels). ${ }^{9}$

This heuristic (Fig. 1) can be used to explore other aspects of research practice - by introducing more and different actors e.g. co-researchers, etc.; by reflecting on the implications of epistemological awareness ${ }^{10}$, but perhaps most importantly, for becoming aware of the nature of situations in which research practice is being conducted.

\section{The nature of situations... and research practice}

There is a rich literature on the nature of situations. Historically the main predisposition of researchers has been to refer to the "problem" without awareness of the literature on the social construction of "problems" and the realization that the "problem metaphor" also conceals

\footnotetext{
8 Inviting you to consider Figure 1 systemically allows me to point out the two adjectives arising from the word system - i.e. systemic (pertaining to an whole) and systematic (linear, or stepby-step). These are often confused. A systemic appreciation of Figure 1 does not, for example, preclude the choice of systems theory for F or, say, SSM (soft systems methodology) for M. These different appreciations of "system" are also often conflated or confused.

${ }^{9}$ In this essay I do not wish to explore how knowledge becomes socially constructed or reified as a result of research and other practices; for this reason I refrain from adding "the production of new knowledge" to my list. My point about second - order reflection is to acknowledge that all research practice takes place in a context (in systems theoretical terms an environment) which is social and which has a history. I note however that to begin to really appreciate how trans-disciplinary research practice might be fostered and conserved these matters have to be drawn into the conversation.

10 I would claim an important realisation that this heuristic can evoke is that we are never, as researchers, independent of the situation (A), and that this model is an abstraction created to reveal a particular set of dynamics which conceals others.
} 


\section{Box 1. Some features of messes and difficulties}

Russell Ackoff first coined the term "mess" in 1974. He did so in response to the insights of two eminent American philosophers, William James and John Dewey. These philosophers recognized that problems are taken up by, not given to, decision-makers and that problems are extracted from unstructured states of confusion. Ackoff $(1974 a, b)$ argued, in proposing his notion of mess that: "What decision-makers deal with, I maintain, are messes not problems. This is hardly illuminating, however, unless I make more explicit what I mean by a mess. A mess is a set of external conditions that produces dissatisfaction. It can be conceptualized as a system of problems in the same sense in which a physical body can be conceptualized as a system of atoms".

From this definition of mess, Ackoff recognized a number of features of messes and difficulties:

(a) A problem or an opportunity is an ultimate element abstracted from a mess. Ultimate elements are necessarily abstractions that cannot be observed.

(b) Problems, even as abstract mental constructs, do not exist in isolation, although it is possible to isolate them conceptually. The same is true of opportunities. A mess may comprise both problems and opportunities. What is a problem for one person may be an opportunity for another - thus a problem can be an opportunity from another perspective.

(c) The improvement to a mess - whatever it may be - is not the simple sum of the solutions to the problems or opportunities that are or can be extracted from it. No mess can be solved by solving each of its component problems/opportunities independently of the others because no mess can be decomposed into independent components.

(d) Simple situations do exist that can be improved by extracting one problem from them and solving it. These are called difficulties and they are seen as exceptions rather than the norm in terms of decisions that are needed in environmental, organizational and other information-related contexts.

(e) The attempt to deal with a system of problems and opportunities as a system - synthetically, as a whole - is an essential skill of a systems practitioner.

the idea of opportunities ${ }^{11}$. The nature of situations cannot be divorced from our own epistemological, theoretical and methodological commitments ${ }^{12}$. Thus for some researchers the situation of interest is a reality independent of the observer in which some phenomena or a phenomenon is of concern. Others, as exemplified within the field of systems scholarship, have coined neologisms to describe situations with particular features. Ackoff (1974) distinguished between messes and difficulties (Box 1); Rittel and Webber (1973) between wicked and tame problems and Schön (1995) between the "swamp" of real life issues and the high ground of continued "technical rationality". What is interesting is that all of these authors were "planners" at one stage and that they coined different terms to describe what was basically the same set of phenomena that they had experienced. They also exemplify reflective research practice.

A more recent neologism, beginning to be conserved amongst researchers who claim commitments to "complexity theories", is the "complex adaptive system" (e.g. Plsek \& Greenhalgh, 2001). From my perspective, this is best seen as part of a lineage of responding to situations which are experienced as uncertain, complex, contested, interconnected (see Steyaert and Jiggins, 2007) by the

\footnotetext{
11 This is an area of scholarship with which I am familiar and which informs our Systems pedagogy at the Open University but it seemed to be unfamiliar to the authors of the paper I was reviewing. The claim can also be made that in some forms of research practice the researcher(s) is/are not open to the situation - their intent, either knowingly or unknowingly, may be to conserve a particular theory or explanation independently of the nature of the situation.

${ }^{12}$ It is these factors as much as any that make inter and trans-disciplinary research difficult under current forms of institutionalising research practice.
}

practice of coining a neologism and reifying the situation as "some thing". From my perspective what makes this particular set of neologisms interesting is that they all characterize a particular type of situation in which most forms of contemporary practice - across all domains seem inadequate. Climate change adaptation is a case in point as well as hunger, as mentioned by Pohl and Hirsch-Hadorn (2008) - below I suggest that taking up and institutionalizing trans-disciplinary research within the current national and international R\&D systems might also be considered in this light.

This leads in some cases to well argued exhortations to develop capacities to manage "wicked problems" (e.g. Australian Government, 2007). At one level this is well and good - and it is a further argument to support the author's main case - to develop ways of doing transdisciplinary research - in the conviction that such a practice will be more effective in responding to such situations. However, there is a trap awaiting the unwary. From my perspective, the trap takes two forms and each can produce unintended consequences from the practices of categorizing and typologising. In many areas of human endeavor the act of categorization is common - in research practice the development of typologies is a frequent form of practice. Although sometimes useful the act of reification and the circulation of the products of reification in academic discourse in particular leads us to lose sight of how these "things" came into existence and, further, the validity or viability in contemporary circumstances, of their on-going use $\mathrm{e}^{13}$. I suggest that on reflection the systemic dynamic depicted in Figure 1 can also be used

\footnotetext{
13 The same can be said for the conservation in discourse of particular metaphors - and particularly their theoretical entailments (see McClintock et al., 2004).
} 
to "model" the practice of typologising. This in turn can blind us to the choices we can make, and thus the responsibility we have, for how we engage with situations. At its simplest we can choose to engage with a situation as if it were a mess, difficulty, complex adaptive system, etc but each choice brings with it different consequences experience shows that engaging with situations as a "difficulty" when they might be better understood as "messes" has the effect of exacerbating the mess! Yet without the distinction "mess"/"difficulty" we may be blind to the dynamics and thus possibilities in the situation.

Whilst the authors recognize that "disciplinary researchers or actors of the life-world think, talk and act differently, since they belong to different thought collectives", they also argue that "researchers and actors of the life-world have to ask themselves about the significance of their own and the other's perception of the problem". For me this commitment to the "problem metaphor" is a cause for concern because it suggests a particular framing (see Shön and Rein, 1994) with the potential to preclude practices in which different actors construct what is at issue (see below and also Steyaert and Jiggins, 2007). I also experience the normative claim as somewhat naive in the face of researchers' epistemological commitments (which may remain hidden even to themselves). In the next line of their paper the argument was made that "this requires relativising their own perspective and accepting other viewpoints as equally relevant." In this claim I find the notion of relativising unhelpful - for me it evokes a dualism, a self-negating either/or choice of the form relativism/objectivism ${ }^{14}$. Of course this may not be the meaning intended but it highlights a set of niggling concerns about the appreciation and understanding of systems scholarship, to which I now turn ${ }^{15}$.

\section{Trans-disciplinary research - informed by, or enacted as, "systems thinking and practice"?}

Figure 2 depicts some of the influences that shape contemporary systems approaches showing the historical lineages to General Systems Theory, cybernetics (first and second-order), operations research, complexity science and so on. The heuristic intent of the figure is to:

- convey the notion that when anyone engages with systems or cybernetic thinking and practice they conserve

\footnotetext{
${ }^{14}$ In Ison et al. (2007a) we describe how in our own practice we distinguish between systemic and systematic practice arguing that historically these have been treated as either/or, a dualism, rather than a duality (a totality). The same understanding can be applied to first and second-order-designing, or first and second-order R\&D (Ison and Russell, 2007).

15 Whilst this reflection was triggered by the paper I reviewed this is, in my experience, a widespread phenomenon.
}

a lineage, and as argued by Ison (2008), it is the connections they make with this history as part of their unfolding social relations that determine, or not, whether they can claim to be using, or drawing on, systems or cybernetic thinking. As Ceruti (1994) observes, "one does not belong to a particular tradition, one produces it" (p. 6);

- explicate the many lineages that give rise to contemporary systems thinking and practice and by so doing, to highlight how often scholars remain ignorant of this history. ${ }^{16}$

Systems is a meta or trans-discipline, but making this claim does not, in my experience, win friends or supporters and, as evidenced by the lack of Systems departments in universities, the academy has not been a conducive place for systems scholarship in an institutionalized form. Making this claim also begs the question of how Systems scholars can contribute to, or facilitate interdisciplinary or trans-disciplinary research. The systems literature is replete with arguments on this topic but I do not have the space to review them here (e.g. see Flood and Carson, 1988; Maiteny and Ison, 2000).

In the context of my review, my main point is that too many authors remain unaware of the different systems and cybernetic lineages, the praxes that have evolved, their constituent concepts and the techniques, tools and methods that are used. It is common for authors to perpetuate a number of misunderstandings of contemporary systems scholarship ${ }^{17}$. These include:

- the ontological trap: today epistemologically aware systemists begin with situations not systems (as ontological entities) and recognize that the construction of a system (of interest) - an epistemological device is a means to effect transformations in situations (e.g. Collins et al., 2007) ${ }^{18}$;

- a lack of appreciation that within the diversity of systems scholarship there are varying epistemological

${ }^{16}$ I do not claim that this depiction is in any way definitive - a major limitation of it is that it does not include the many valid French, German and Spanish, and possibly other, contributions to contemporary systems approaches. This in itself also highlights how the different language communities give rise to intellectual silos.

17 Like all disciplinary fields Systems is not a homogeneous field - how it understands itself is contested.

18 It was Checkland who made this important intellectual break when he differentiated "hard" from "soft" systems. (see Checkland 1999) If the historical context is understood then one can appreciate why he coined these names but unfortunately they perpetuate the trap Checkland was trying to escape-it leads those who engage with his work in a superficial manner to see systems as "types" and not as devices to engage with situations. Elsewhere I have argued that the soft/hard dualism is no longer helpful and have made the case for considering the systemic with the systematic (and their underlying epistemologies) as a duality, a whole (see Ison et al. 2007). 


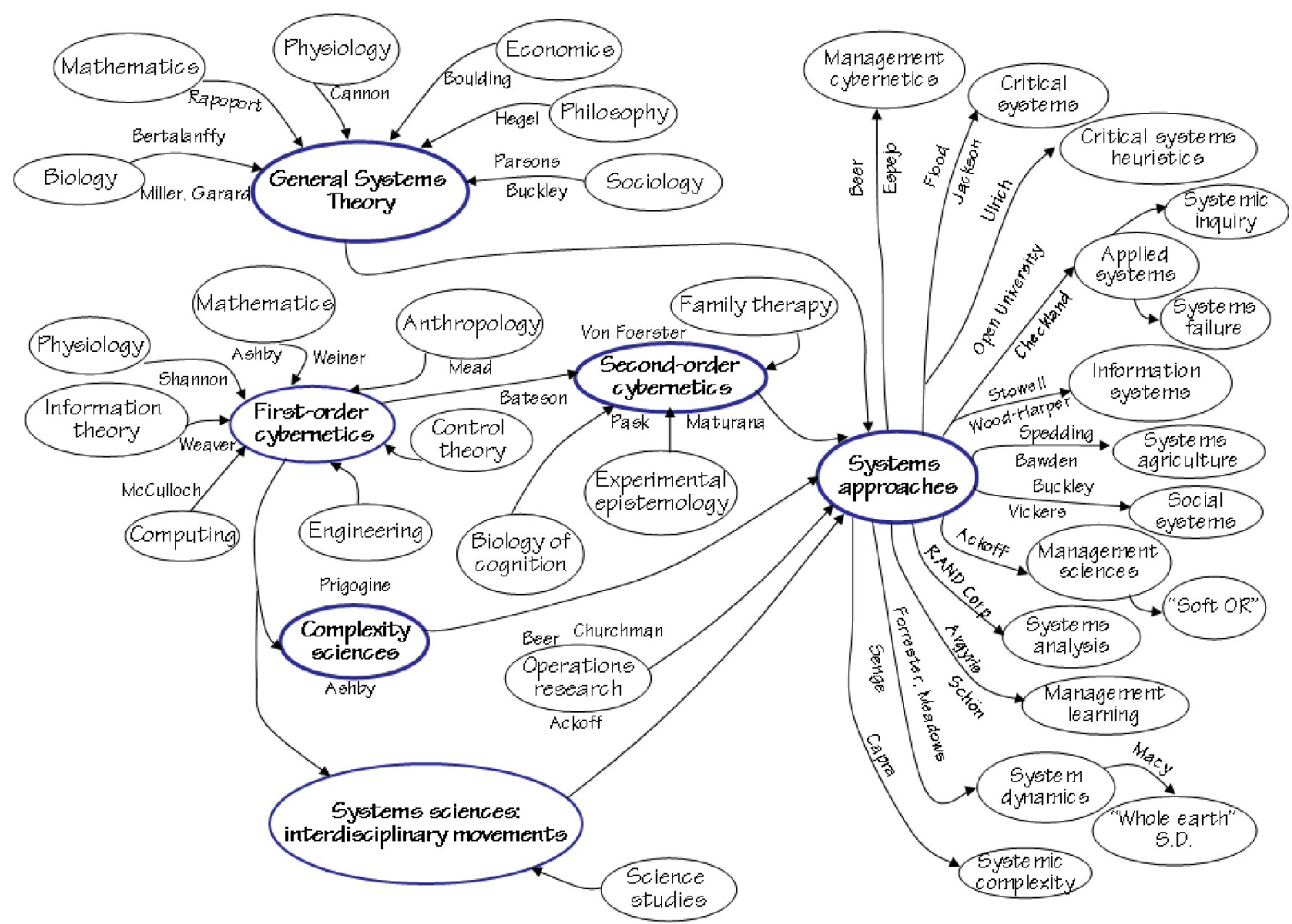

Fig. 2. A model of different influences that have shaped contemporary systems and cybernetic approaches (source: Ison, 2008).

commitments and that this flavors the debates, discourses and practices.

So for example, when Pohl and Hirsh-Hadorn (2008) claim that "the specific trans-disciplinary challenges for an explicit handling of the normative orientation arises in interrelating descriptive, normative and practice-oriented forms of knowledge. We distinguish these three forms of knowledge that are relevant in TR as follows: Systems knowledge as knowledge of the current status; Target knowledge as knowledge about a target status; and transformation knowledge as knowledge about how to make the transition from the current to the target status..." I would make a counter claim based on my use and adaptation of SSM ${ }^{19}$ (Soft Systems Methodology). My claim would be that effective and epistemologically aware use of SSM already incorporates these three forms of knowledge (though I would prefer to say knowing). As explained

\footnotetext{
${ }^{19}$ In using this example I am not attempting to privilege SSM above other systems approaches, merely to reflect on my experience; in my case SSM is a theoretical framework and it is a trap to merely consider it as a methodology - or even worse a method!
}

above, within SSM the "knowledge" that is produced is about the framework of ideas/theory, the methodology and the situation and incorporates a range of systemic understandings including the nature of transformations, measures of performance (a better term than targets) and strategies for action based on accommodations between different actors ${ }^{20}$. In distinguishing "system knowledge" the authors also reveal, knowingly or unknowingly, a position in regards to the systems ontological trap described above ${ }^{21}$.

\footnotetext{
20 There is an expanding evidence base about how the use of targets in the UK by the New Labour government has led to systemic failure, i.e. the creation of targets induces behaviour to meet the targets, which may not be connected with the phenomenon to which the targets applied in the first place!

${ }_{21}$ This is commonplace - in a recent conversation about a new UK Foresight programme concerned with Land Use Futures, a common expression by many was "the land use system". One way out of this trap is the deployment of "as if" - e.g. Let us think about UK land use as if it were a system. Expressed in this way, it enables an inquiry into understandings of purpose, boundary judgements, connectivities etc. to be pursued.
} 
To finish this section, let me offer some reflections based on the set of figures initially offered by Pohl and Hirsch-Hadorn (2008) ${ }^{22}$. My comments are informed by 35 years of teaching "Systems" at the Open University (UK) where we have developed "diagramming" as a major skill for engaging with messes (see Ison, 2001). Figure 1, it was claimed, "describes the structure of a trans-disciplinary research project as a system". The "elements of the system" are presented and the claim made that the term "system" refers to the interaction of these elements during the research process e.g. by "discussing" what the problem is about, by "investigating" the problem, by "deliberating" about values and goals, or by "developing" measures? ${ }^{23}$ From the perspective of OU teaching standards, Figure 1 was not a very satisfactory diagram as it follows no protocol for systemic diagramming. For example, in naming the so-called "elements" different types of "variables" or "elements" are conflated as inputs e.g. action research, a name for a methodological approach, and molecular biology a name for a sub-field of science. Moreover, merely putting these together does not create trans-disciplinary research. If one examines the accompanying text, what seems to be of importance are the verbs highlighted above i.e. it is better considered as a system to discuss, investigate, deliberate and develop i.e. a set of activities (practices) that are better modeled using activity modeling with verbs, which is also a key aspect of SSM practice ${ }^{24,25}$.

In summary, my engagement with the paper and thus the transformation in my emotioning arose through my particular traditions of understanding arising from my engagement with systems scholarship (Fig. 2), my interest in the development of systems praxeology, including understanding research practice as a particular systemic dynamic (Fig. 1) and an appreciation of the implications of reifying situations independently of the dynamic of their distinction. In addition my reactions were influenced by my own experiences of participating in and managing inter- and trans-disciplinary R\&D, experiences to which I now turn.

\footnotetext{
${ }^{22}$ My comments about diagramming, or figure construction, apply well beyond the specific paper under review; in making these reflections I am inviting all authors to consider how congruent a figure is with the concepts it is trying to convey and how well it is designed as a heuristic for communication or triggering new distinctions in the reader.

${ }^{23}$ I have added inverted commas to the verbs.

${ }^{24}$ In the original submission I found Figure 2 very abstract and not conveying a great deal; other forms of diagramming could have been used (Open University, 2006).

${ }^{25}$ Considering what is needed in terms of verbs (activities) would probably also highlight some that are missing e.g. the need to define who is doing the activities and who controls the interpretations. "Professionals always talk about involving clients and other actors in deliberations while they control the questions and the interpretation of the answers" (Eli Benneker, pers. comm., 2008).
}

\section{Considering "trans-disciplinary research" as social learning?}

The authors claim that "TR deals with problem fields in such a way that it can:

(a) grasp the complexity of problems;

(b) take into account the diversity of scientific and lifeworld perceptions of problems;

(c) link abstract and case-specific knowledge, and

(d) develop knowledge and practices that promote what is perceived to be the common good."

It is easy to say this but what does this actually mean? And how has this been done by others? These concerns, valid as they are, were not new to me. A concern I had as I read the paper was the absence of references to the experiences within agriculture and rural development circles of multi-, inter- and trans-disciplinary approaches to $R \& D$ practice including participatory and systemic action research (e.g. Chambers \& Jiggins, 1987; Röling \& Wagemakers, 1998), systems agriculture and systemic development (Bawden \& Packham, 1993; Ison et al., 2007b) and activities within the farming systems (e.g. Biggs, 1995) and learning networks (e.g. Hubert, et al., 2000). More recently there have been developments under the rubric of social learning which can inform the development and institutionalization of trans- or inter-disciplinary practices (Fig. 3$)^{26}$.

Figure 3 is an heuristic, derived from empirical research which elucidates a set of "key variables" that can constrain or enhance the transformation of issues, in situations of complexity, uncertainty, conflict and interdependency through changes in understanding and practices (where neither is prime). The emergent property of such a transformation can be social learning (understood as an effective performance among multiple stakeholders in a complex situation). As outlined in SLIM (2004a), this heuristic can be used in a number of ways. It could be used as a way of understanding the challenges facing the transformation of a situation in which TR research is not commonplace to one where it is!

The authors draw on the distinctions made by Gibbons, et al. (1994) between Mode 1 and Mode 2 knowledge.

\footnotetext{
26 This observation raises two points of interest: (i) what is the responsibility of a referee when they are aware that a significant element of the available literature appears to be missing from consideration? As a PhD supervisor, I see it as my role to ensure that a student is aware of the whole territory even if only part of it is engaged with. A quick scan of Hirsch-Hadorn et al. (2008) shows one point of connection with the literature I refer to (i.e. Hubert, et al., 2008) but these understandings do not seem to appear in the major synthesis chapters; (ii) how different communities of conversation and practice, despite similar concerns, can remain isolated - this in itself has implications of how trans-disciplinary research might be understood and institutionalised and the important role of boundary spanning, as described by Wenger (1998).
} 


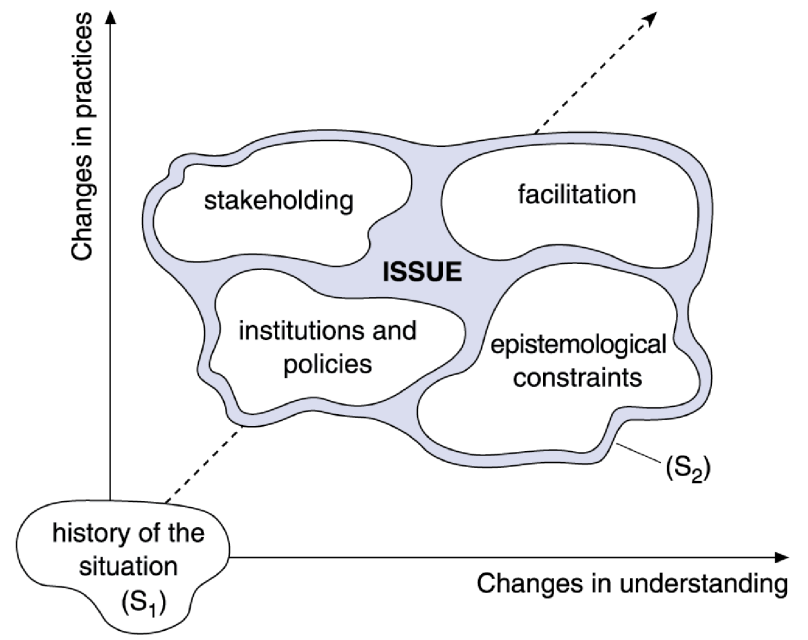

Fig. 3. In the SLIM (Social Learning for the Integrated Management and sustainable use of water) research, we have been concerned in particular with how five variables interact and are mediated by learning processes to shape issues and transform particular situations. These variables include history, stakeholding, facilitation, institutions and policies, and epistemological constraints (Source: adapted from Steyaert and Jiggins, 2007). ${ }^{27}$

Initially I too found these distinctions helpful but have come to the view that because they lack a focus on praxis, the distinctions of themselves offer little to aid capacity building (for Mode 2) and for dealing with the politics of institutionalizing Mode 2 ways of knowing. One could argue that those people enthusiastic about Mode 2 are increasingly marginalized in Universities and the overall "R\&D system" despite the rise of rhetoric that suggests the contrary (e.g. third mission or knowledge transfer activity in the UK). The institution/policy variable in Figure 3 in our understanding also involves the active (and political) process of institutionalizing. Using this heuristic would enable an exploration of the historical, institutional and policy context for doing trans-disciplinary research in a given context. It draws attention to the need for actively building stakeholding in any joint activity, highlights the role of facilitation and draws attention to the need to surface the different epistemological commitments among stakeholders. Appreciating the nature of learning processes is also key to managing a transformation process (SLIM, 2004b). I make these points because the heuristic enables an exploration of a complex situation (doing trans-disciplinary research) as a form of praxis involving a systemic dynamic of changes in understanding and practices and transformations in situations (of mutual interest).

\footnotetext{
27 In the original SLIM heuristic we referred to "ecological constraints" but in the sense of the ways of knowing that give rise to claims about these - for this reason I refer here to epistemological constraints as a higher order concept than "ecological constraints".
}

The understanding that informs this heuristic and our practices, as an interdisciplinary research team, in conducting the research from which its current form was developed also leads me to question the value of the recent interest in "integration" and, thus, the utility of trying to build a praxis called "integration science". For example the following questions are often, in my experience, not answered: What is being integrated? What is it that one would need to experienced to claim that integration had occurred... or not? ${ }^{28}$

Pohl and Hirsh-Hadorn (2008) claim that "integration takes place during one or more rounds of exchange among the experts. The notion of expert is not restricted to the disciplinary researchers but also includes actors of the lifeworld'. Elsewhere they say: "based on such a placement within the community of perspectives, the perspectives can begin to interact". In my experience the processes they suggest are not easy to design and facilitate and begs the question as to what is "exchanged". Wenger's (1998) work on communities of practice can help here. Also an appreciation that humans live in language - and at the end of the day this is all we have at our disposal for orchestrating joint action ${ }^{29}$.

Let me also point out that "integration" at the theoretical or methodological level may not be feasible or desirable. In our SLIM research (Blackmore et al., 2007) we (as four different country teams comprising researchers with social and natural science backgrounds) became concerned with "the differences that make a difference", to paraphrase Gregory Bateson (1979) ${ }^{30}$. Our concern arose from an awareness that failing to appreciate differences can lead to losses, particularly sources of new insight and innovation, recognizing that at the same time we had to build a language community in which some common understanding was possible. This, as the authors demonstrate, is a perennial problem for inter and transdisciplinary research. In our work we took a "double

\footnotetext{
${ }_{28}$ Eli Benneker (pers. comm., 2008) in feedback on this essay said in response to these questions: "Easy. Integration occurs when necessary uncertainties are incorporated in the discourse requiring inclusion of other disciplines." At one level his point is well made i.e. when we are open to the limitations of our own traditions of understanding, a case for integration could be made, but as I argue the key is in the unfolding praxis, especially if that praxis does not allow for "news of difference".

29 The author's claim that "such problems can be effectively addressed by making explicit what important terms mean, e.g. in a glossary. Another way of facilitating mutual understanding through effective communication is by deliberately using everyday language and avoiding scientific terms". In my experience this is necessary but not sufficient - in our research for example it was insightful to understand how the word "institution" was understood in different cultures - in practical terms the issue was to become aware of the implications of the differences rather than to stabilise the term.

30 A fifth country team made methodological contributions across all groups.
} 
look" - we looked at the differences that made a difference to the research activities of the four participating country teams whilst at the same time exploring how "social learning" might contribute something different to policy and research practice - something that does not negate other endeavors but teased out those differences that might make a difference to the over-arching goals of structural renewal in water management.

In summary then, when there is awareness that each individual and/or group acts out of their own traditions of understanding then understanding is not something that can ever be fully "shared". "It follows that when comparison between cases (or other research findings) is under consideration (i) control is not possible - ethically and situationally; (b) case control comparisons do not work - these are non-random samples and each is historically and socially situated (as are the researchers), so (c) there is a need for a meta-level process of co-learning which creates an emergent core of common understanding (what we can claim that we have in common) but where the differences are equally valued and articulated" (Blackmore et al., 2007). This is a dialectical process as outlined by Steyaert and Jiggins (2007). A major implication of our SLIM work was that we need methodologies for synthesis or sense making, not comparison and unifying as if there were a set of objective social "truths" waiting to be revealed. Methodologies for sense-making are in short supply but the SLIM heuristics (e.g., Fig. 3) can be used methodologically for such purposes.

\section{Concluding remarks}

To reiterate I welcome the interest and contribution of this research group (and network) to this topic. Also the opportunity NSS provides to air these issues. In this essay I have tried to provide some explanations for the transformation in my emotioning - from excitement to anxiety - as I engaged with the paper. ${ }^{31}$ I have also highlighted some areas of theory as well as research practice that, from the perspective of my own experiences, seem to be missing or perhaps misrepresented.

Let me offer some final reflections on the desirability or otherwise of the "trans-disciplinarity" project espoused by the authors. My own question is, given that I understand Systems to be a meta or trans-discipline, why do we need another one rather than enhancing the utilization

\footnotetext{
31 My preference is for explications that are grounded in experience; I find abstract typologising somewhat unsatisfactory. In the case of Pohl and Hirsch-Hadorn's (2008) paper they were, I perceive, explicating at two levels of abstraction (and experience) (i) what claims can be made about doing TD research?; and (ii) what claims can be made about the act of synthesising experiences (from a Handbook/conference) about doing TR research? These are two different experiential domains.
}

of the one we have? For example, Jackson (1995) argued that systems scholars should "abandon the notion that Systems has a subject matter of its own" and apply it to other disciplines so that it becomes entirely critical. His metaphor was that it should become the handmaiden of other disciplines. This proposition is certainly worthy of further consideration. My own experience is that Jackson's prescription would not work at the moment because Systems scholarship, in the sense depicted in Figure 3, is so poorly institutionalized in higher education and research services. To be the "handmaiden" of other disciplines, systems, as an area of scholarly concern, will also always have to build and rebuild the intellectual ground on which it chooses to stand -i.e. through changes in both practice and understanding (Fig. 3).

There is also the notion of "transcendence" implied by claims to "trans-disciplinary activity" - is this merely "emergence" by another name? If so then systemists would seem well equipped to work with people from other disciplines to develop understandings and practices for emergence. I am in general agreement with Bammer (2005) who argues for a new specialisation in science... around the three pillars of systems thinking and complexity science, participatory methods and knowledge management", though I would express the need somewhat differently. In my view commitments to a "systems science" at the expense of "systems praxis" have held back the contributions that systems approaches can make to improving complex issues ${ }^{32}$. Whilst participation is important and necessary I no longer regard it as sufficient - social learning has, in my view, more to offer (see Collins and Ison, 2006). I would also specify third generation knowledge management (and beyond) as well as the emerging understandings about communities of practice. Above all else there is an urgent need to build capacity and to create conducive institutional arrangements for this form of praxis to flourish.

\section{References}

Ackoff, R.L., 1974a. The systems revolution, Long Range Planning, 7, 2-5.

Ackoff, R.L., 1974b. Redesigning the Future, New York, Wiley.

Australian Government, 2007. Tackling wicked problems. A public policy perspective. Canberra, Australian Public Service Commission. (Accessed at http://www.apsc.gov.au/ publications07/wickedproblems.htm, 1st April 2008).

Bammer, G., 2005. Integration and Implementation Sciences: Building a New Specialization, Ecology and Society 10, 2, 6, http://www.ecologyandsociety.org/vol10/iss2/art6/

\footnotetext{
32 However I would not seek to build a new specialisation in science, but for science, or more appropriately, R\&D; this is another reason why I see attempts to build an "integration science" to be misconceived. I would also claim that how we understand technology i.e. a philosophy of technology (techne) needs to be built into the discourse.
} 
Bateson, G., 1979. Mind and Nature: A Necessary Unity (Advances in Systems Theory, Complexity, and the Human Sciences), New Jersey, Hampton Press.

Bawden, R.J., Packham, R.G., 1993. Systemic praxis in the education of the agricultural practitioner, Systems Practice, 6, 7-19.

Benneker, E., 2008. personal communication.

Biggs, S.D., 1995. Farming systems research and rural poverty: Relationships between context and content, Agricultural Systems, 47, 161-174.

Blackmore, C.P., Ison, R.L., Jiggins, J., 2007. Social learning: an alternative policy instrument for managing in the context of Europe's water. Editorial, Special Edition, Environmental Science E Policy, 10, 6, 493-498.

Ceruti, M., 1994. Constraints and Possibilities. The Evolution of Knowledge and the Knowledge of Evolution, Switzerland, Gordon \& Breach.

Chambers, R., Jiggins, J., 1987. Agricultural research for resourcepoor farmers. I: Transfer-of-technology and farming systems research, Agricultural Administration and Extension, 27, 35-52.

Checkland, P.B., 1985. From optimizing to learning. A development of systems thinking for the 1990's, Journal of Operations Research Society, 36, 9, 757-767.

Checkland, P.B., 1999. Soft Systems Methodology: A 30 Year Retrospective, Chichester, John Wiley \& Sons.

Checkland, P.B., Holwell, S., 1998. Information, Systems and Information Systems, Chichester, John Wiley.

Collins, K.B., Ison, R.L., 2006. Dare we jump off Arnstein's ladder? Social learning as a new policy paradigm. Proceedings PATH (Participatory Approaches in Science \& Technology) Conference, 4-7 June 2006, Edinburgh.

Collins, K., Blackmore, C., Morris, D., Watson, D., 2007. A systemic approach to managing multiple perspectives and stakeholding in water catchments: Some findings from three UK case studies. Environmental Science E Policy 10, 6, 564-574.

Flood, R. L., Carson, E., 1988. Dealing with Complexity. An Introduction to the Theory and Application of Systems Science, New York, Plenum Press.

Gibbons, M., Limoges, C., Nowotny, H., Schwartzman, S., Scott, P., Trow, M., 1994. The New Production of Knowledge - The Dynamics of Science and Research in Contemporary Societies, London, Thousand Oaks, New Delhi, Sage.

Hirsch Hadorn, G., Hoffmann-Riem, H., Biber-Klemm, S., Grossenbacher-Mansuy, W., Joye, D., Pohl, C., Wiesmann, U., Zemp, E. (Eds), 2008. Handbook of Transdisciplinary Research, Dordrecht, Springer.

Hubert, B., Ison, R.L., Röling, N., 2000. The "problematique" with respect to industrialised country agricultures, in LEARN Group (Eds), Cow up a Tree. Knowing and Learning for Change in Agriculture. Case Studies from Industrialised Countries, Paris, INRA Éditions, 13-30.

Hubert, B., Meuret, M., Bonnemaire, J., 2008. Shepherds, sheep and forest fires: a reconception of grazingland managment, in Hirsch Hadorn G., Hoffmann-Riem H., Biber-Klemm S., Grossenbacher-Mansuy W., Joye D., Pohl C., Wiesmann U., Zemp E. (Eds), Handbook of Transdisciplinary Research, Springer, Dordrecht, 103-126.

Ison, R.L., 2001. Systems practice at the United Kingdom's Open University, in Wilby J., Ragsdell G. (Eds), Understanding Complexity, Kluwer Academic/Plenum Publishers, 45-54.

Ison, R.L., 2008. Systems thinking and practice for action research, in Reason, P., Bradbury, H. (Eds.), The Sage Handbook of Action Research Participative Inquiry and Practice (2 ${ }^{\text {nd }}$ ed.), London, Sage Publications, 139-158.
Ison, R.L., Russell, D.B., 2000. Exploring some distinctions for the design of learning systems, Cybernetics and Human Knowing, 7, 4, 43-56.

Ison, R.L., Russell, D.B. (Eds), 2007. Agricultural Extension and Rural Development: Breaking Out of Knowledge Transfer Traditions, Cambridge, UK, Cambridge University Press.

Ison, R.L., Schlindwein, S., 2006. History repeats itself: current traps in complexity practice from a systems perspective. Proc. 12th Australia New Zealand Systems Society (ANZSYS) Conference, "Sustaining our Social and Natural Capital", Katoomba, 3-6 December 2006.

Ison, R.L., Blackmore, C.P., Collins, K.B., Furniss, P., 2007a. Systemic environmental decision making: designing learning systems, Kybernetes, 36, 9/10, 1340-1361.

Ison, R.L., Bawden, R.D., Mackenzie, B., Packham, R.G., Sriskandarajah, N., Armson, R., 2007b. From sustainable to systemic development: an inquiry into transformations in discourse and praxis, invited Keynote Paper, Australia New Zealand Systems Conference 2007, "Systemic development: local solutions in a global environment", Auckland, New Zealand, 2-5 December 2007.

Jackson, M., 1995. Personal communication.

Maiteny, P.T., Ison, R.L., 2000. Appreciating systems: critical reflections on the changing nature of systems as a discipline in a systems learning society, Systems Practice $\mathcal{E}$ Action Research, 16, 4, 559-586.

Maturana, H., 1988. Reality: The search for objectivity or the quest for a compelling argument, Irish Journal of Psychology, 9, 25-82.

Maturana, H., Varela F., 1987. The Tree of Knowledge: The biological roots of human understanding, Boston, New Science Library, Shambala Publications.

McClintock, D., Ison, R.L., Armson, R., 2003. Metaphors of research and researching with people, Journal of Environmental Planning and Management, 46, 5, 715-731.

Open University, 2006. Techniques for Environmental Decision Making, Milton Keynes, UK, The Open University.

Plsek, P., Greenhalgh, T., 2001, The challenge of complexity in health care, British Medical Journal, 323, 625-8.

Pohl, C., Hirsch Hadorn, G., 2007. Principles for Designing Transdisciplinary Research - proposed by the Swiss Academies of Arts and Sciences. Zimmermann A., translator, München, Oekom Verlag.

Pohl, C., Hirsch Hadorn, G., 2008. Methodological challenges of transdisciplinary research. Natures, Sciences Sociétés, 16, 111.

Pohl, C., van Kerhoff, L., Bammer, G., Hirsch Hadorn, G., 2008. Integration, in Hirsch Hadorn G., Hoffmann-Riem H., BiberKlemm S., Grossenbacher-Mansuy W., Joye D., Pohl C., Wiesmann U., Zemp, E. (Eds), Handbook of Transdisciplinary Research, Dordrecht, Springer, 411-424.

Rittel, H.W.J., Webber, M.M., 1973. Dilemmas in a general theory of planning, Policy Science, 4, 155-69.

Röling, N., Wagemakers, A., (Eds.), 1998. Facilitating Sustainable Agriculture. Participatory learning and adaptive management in times of environmental uncertainty, Cambridge, Cambridge University Press.

Russell, D.B., Ison, R.L., 2007. The research-development relationship in rural communities: an opportunity for contextual science, in Ison, R.L., Russell, D.B. (Eds), Agricultural Extension and Rural Development: Breaking out of Knowledge Transfer Traditions, Cambridge University Press, Cambridge, UK, 10-31. 
Schön, D.A., 1995. The new scholarship requires a new epistemology, Change, November/December, 27-34.

Schön, D.A., Rein, M., 1994. Frame reflection. Toward the resolution of intractable policy controversies, New York, Basic Books.

SLIM, 2004a. SLIM Framework: Social Learning as a Policy Approach for Sustainable Use of Water, available at http: //slim.open.ac.uk.

SLIM, 2004b. The Role of Learning Processes in Integrated Catchment Management and the Sustainable Use of Water. SLIM Policy Briefing 6, available at http://slim.open.ac.uk.
Steyaert, P., Jiggins, J., 2007. Governance of complex environmental situations through social learning: a synthesis of SLIM's lessons for research, policy and practice, Environmental Science and Policy, 10, 6, 575-586.

Wenger, E., 1998. Communities of Practice: Learning Meaning and Identity, Cambridge University Press, Cambridge. 